\title{
A relação entre autonomia e rede de apoio social na percepção de adolescentes com deficiência intelectual ${ }^{1}$
}

\author{
SANTOS, Larissa Cristina Alves dos \\ SILVA, Danielle Sousa da
}

\begin{abstract}
Resumo: A autonomia das pessoas com deficiência intelectual (DI) ainda é colocada em questão no âmbito social devido à crença de incapacidade que circunscreve as pessoas com deficiência. No que tange as pessoas com deficiência intelectual este descrédito, em geral, se refere à possibilidade de exercerem suas escolhas e decisões frente a projetos de vida, amizades, gerenciamento da vida financeira e pessoal. Diante disso, esse trabalho se propõe refletir a relação estabelecida entre o exercício da autonomia e a rede de apoio social na percepção de adolescentes com deficiência intelectual. A investigação foi realizada por meio de estudo de caso de 2 (dois) estudantes com deficiência intelectual. Os adolescentes foram entrevistados individualmente por meio do Social Network Guide (SNG) (FORRESTER-JONES, GRANT, 1997), e posteriormente acessados por meio de entrevistas semiestruturadas com o objetivo de ampliar as análises em conjunto com os resultados evidenciados no SNG. Os resultados obtidos pelo SNG revelaram que a rede de apoio social dos adolescentes com deficiência intelectual é composta mormente pela família nuclear, além de uma rede restrita de colegas no âmbito da escola. Assim, verifica-se a relevância da continuidade da presente investigação a fim de ampliar a compreensão acerca da percepção do adolescente com deficiência intelectual e seus familiares sobre a relação estabelecida entre a rede de apoio social e as possibilidades de ação autônoma da pessoa com DI frente as suas escolhas e decisões.
\end{abstract}

\section{Palavras chaves: Apoio Social. Deficiência Intelectual. Família.}

\begin{abstract}
The autonomy of people with intellectual disabilities (ID) is still in question in the social sphere due to the belief in incapacity that circumscribes people with disabilities. With regard to people with intellectual disabilities, in general, it refers to the possibility of exercising their choices and decisions in relation to their life projects, friendships, financial and personal life management. Therefore, the work shows a relationship between the exercise of autonomy and a social network of support in the perception of adolescents with intellectual disability. The research was carried out through the case study of 2 (two) students with intellectual disability. The students were interviewed by the Social Networking Guide (SNF) (FORRESTER-JONES, GRANT, 1997), and later accessed through semi-structured interviews (SNG). The results obtained by the SNG revealed that the social network of support for adolescents with disabilities is mostly composed by the nuclear families, in addition to a restricted network of colleagues in the school. Thus, it is verified the relevance of the continuity of the present investigation in order to broaden the understanding about the perception of adolescents with intellectual disabilities and their relatives about the relationship established between the network of social support and the possibilities of autonomous action of the person with ID their choices and decisions.
\end{abstract}

\section{Keywords: Social support. Intellectual Disability. Family.}

1Este estudo integra uma pesquisa em andamento do Programa de Pós-Graduação em Psicologia intitulada: "Repercussões das crenças, valores e atitudes sobre inclusão no processo de desenvolvimento da pessoa com deficiência na escola", financiada pela Fundação de Apoia à Pesquisa do Distrito Federal (FAP/DF) e aprovada pelo Comitê de Ética e Pesquisa da Universidade Católica de Brasília (CEP/UCB). 


\section{Introdução}

O Relatório Mundial sobre a Deficiência, publicado pela Organização Mundial da Saúde em 2011, que traz a concepção de que a deficiência deve ser encarada como uma questão de direitos humanos e a define como "complexa, dinâmica, multidimensional, e questionada" (OMS, 2011, p. 4) pelos contextos históricos e sociais que vem se constituindo e reconstituindo na sociedade. Esse mesmo relatório ainda endossa a compreensão de que o ambiente possui um grande impacto sobre a experiência e extensão da deficiência, sendo ele um agente que afeta na vivência do sujeito (OMS, 2011), dispondo-se a ser um objeto de mudança para que o acesso de facilitadores produza uma maior acessibilidade para a construção de novas experiências e interações sociais.

Considerando a definição que circunscreve a deficiência enquanto "complexa, dinâmica, multidimensional e questionada" (OMS, 2011) observa-se que o meio social em que a pessoa com deficiência está inserida deve considerar e se adequar a estes aspectos dispondo da criação de ambientes mais acessíveis para a inclusão e à favor da diversidade, garantindo efetivas condições de participação social, uma vez que, as barreiras sociais e físicas são capazes de demarcar a trajetória de vida dessas pessoas.

Essas reflexões evidenciam a carência de estudos sobre a participação e inclusão social as pessoas com deficiência. A este fator atribuímos dois fatores, o primeiro refere-se à quantidade de pessoas com algum tipo de deficiência autodeclarada no país; considerando a estimativa dos dados do último Censo Demográfico realizado no país mapeado pelo Instituto Brasileira de Geografia e Estatística (IBGE, 2010), onde cerca de 24\% da população, aproximadamente 45 milhões de brasileiros, se declararam com algum tipo de deficiência. É o segundo fator atribui-se a categoria do capacitismo que ainda hoje assola as pessoas com deficiência, que inclui "atitudes preconceituosas que hierarquizam sujeitos em função da adequação de seus corpos a um ideal de beleza e capacidade funcional” (MELLO, 2016, p. 3266).

Mediante as considerações tecidas acima emergiram neste estudo as seguintes indagações: Como os adolescentes com deficiência intelectual e seus familiares percebem a relação estabelecida entre a autonomia e rede de apoio social? Em um desdobramento: Como os adolescentes com deficiência intelectual e seus familiares viabilizam vivências autônomas mediante a rede social? Em face destas questões o objetivo deste estudo visa compreender os sentidos subjetivos atribuídos acerca do exercício da autonomia frente à rede de apoio social pelos adolescentes com deficiência intelectual e seus familiares.

Esta pesquisa compreende um estudo inspirado na proposta metodológica construtivointerpretativo da Epistemologia Qualitativa de González Rey (2005) como meio de compreender o exercício da autonomia de 2 (dois) adolescentes com deficiência intelectual, bem com as interações promotoras de autonomia estabelecidas por seus familiares frente à rede social de apoio. Os resultados que emergiram neste estudo são provocadores para refletir como o espaço social, em especial, a escola e a família, se constitui como um profícuo espaço de desenvolvimento subjetivo do adolescente com deficiência intelectual em prol do exercício da autonomia frente à sua rede social.

As interações sociais e as redes sociais, efetuadas entre o homem e o meio são as que proporcionam o desenvolvimento. Permitir que esse sujeito tenha a liberdade para a interação 
social com destino a construção de relações favorece na formação de uma pessoa ativa para uma vida participativa exercendo sua autonomia e reduzindo situações de inferioridade. A perda da autonomia se dá quando as pessoas que compõem a rede social do sujeito com deficiência intelectual enxergam suas habilidades com negligência, colocando-a como insuficiente ou incapaz. É importante que o suporte familiar esteja presente nas situações do cotidiano, impulsionando o sujeito com deficiência a se constituir como um ser autônomo que seja capaz de fazer escolhas de acordo com seus próprios desejos, promovendo a liberdade e independência. Desse modo, isso proporcionará autonomia tanto no trabalho, no meio social e na construção de sua identidade e autopercepção.

\section{Referencial Teórico}

A família, sendo a primeira fonte de apoio social e afetivo de uma criança, é um importante fator para impulsionar o seu desenvolvimento pessoal e cognitivo, beneficiando assim suas relações com o ambiente social (COLNAGO, 2000). A rede de apoio se mostra um importante aspecto que deve estar acompanhado do deficiente intelectual. A literatura apresenta que a forma como a família se adapta para oferecer os recursos necessários para uma criança com deficiência é um fator que influencia nas relações familiares e sociais da mesma. Douma, Dekker e Koot (2006) propõem que a família necessita de suporte profissional pois os mesmos apresentam altos níveis de estresse parental. Famílias que não procuram esse suporte geralmente se dão pelo filho não ter um comprometimento grave ou por não saber onde achar esse suporte resolvendo as dificuldades eles mesmos.

A criança com deficiência intelectual necessita da rede social de apoio e suporte familiar e profissional necessário para sua inserção em espaços sociais para seu desenvolvimento. Bailey (2007) apresenta que os comportamentos de crianças estão altamente influenciados pelo ambiente familiar como as interações e expressões emocionais. Conforme Collins e Feeney (2015), os sujeitos que estão devidamente inseridos em um contexto social possuem um melhor bem-estar e saúde mental, oportunizando assim os melhores relacionamentos.

As relações familiares afetam o sujeito por ter um caráter social com o envolvimento de significados. O ambiente em que a criança se encontra tem efeitos sobre a mesma conforme as suas características de personalidade. Outro aspecto apontado que pode influenciar no desenvolvimento de uma criança com deficiência é a respeito da adaptação da própria família à deficiência e suas peculiaridades. Portanto, para que a família se adapte às mudanças, é necessário que haja uma rede de apoio e suporte de serviços profissionais apropriados (FIAMENGHI, MESSA, 2007).

Considerando a proposta deste estudo em investigar a Deficiência Intelectual (DI) observa-se a necessidade de demarcar a definição desta deficiência a partir da American Association on Intellectual and Developmental Disabilities (AAIDD, 2016), como: "uma deficiência caracterizada por limitações no funcionamento intelectual e no comportamento adaptativo, que envolve habilidades conceituais, sociais e práticas; sendo que essa deficiência se origina antes dos 18 anos de idade. No que tange, o quantitativo populacional deste grupo estima-se que no Brasil, de acordo com o IBGE (2010), que 0,8\% da população brasileira 
apresenta algum tipo de deficiência intelectual, sendo que a maioria $(0,5 \%)$ já nasceu com as limitações.

Mediante o conceito de deficiência intelectual da AAIDD e o quantitativo da população com deficiência intelectual no Brasil, questiona-se sobre as possibilidades de inclusão social que estão sendo fomentadas e ofertadas para este público, sobretudo a partir da mediação de seus familiares. Isso porque, a depender do apoio que a pessoa com deficiência dispõe para transpor os limites imbricados na interação entre biológico e o social está poderá alcançar diferentes níveis de participação social (HOLANDA et. al., 2015).

A rede social de apoio de acordo com Holanda et al (2015) compreende "qualquer informação, falada ou não, e/ou auxílio material, oferecidos por grupos e/ou pessoas que se conhecem, que resultam em efeitos emocionais e/ou comportamentos positivos". Desta maneira, verifica-se a necessidade de possibilitar intervenções com o foco na ampliação da rede social de apoio das pessoas com deficiência intelectual, sobretudo em função das barreiras sociais que são designadas as pessoas com deficiência.

Ambientes familiares acolhedores oferecem oportunidades para que seja estabelecido práticas para enfrentamento de problemas, portanto, é necessário a promoção da autonomia e de práticas socais por meio da família para que gerem comportamentos que possibilitem bemestar interpessoal (CARDOZO, SOARES, 2011). A autonomia faz parte do desenvolvimento do sujeito, e deve ser fomentada desde o início da adolescência para que o sujeito faça parte de um processo de responsabilidade como autor de sua própria história e de escolha para relações sociais.

Contudo, é necessário refletir sobre a importância de fomentar a autonomia para adolescentes com deficiência intelectual em se regular e de se autodeterminar para fazer escolhas, levando em conta seus desejos e necessidades simultaneamente (BISSOTO, 2014), de maneira a reconhecer e enaltecer as suas potencialidades, ao invés de demarcar as limitações. Desta maneira, vale ressaltar que a partir do momento que a autonomia é exercida em meio às vivências pessoais, identidades são construídas e "essas identidades são formadas por incentivos, sanções, pelo assumir de diferentes papéis, por um sentido de competência e autonomia" (BISSOTO, 2014, p. 7). Assim, considera-se que o exercício de autonomia também contribui para a ampliação, diversificação e crescimento da rede social de apoio, que se configura como agente influenciador para a autoestima, interação social e a qualidade na saúde mental.

Lev S. Vygotsky (1896-1934) apresenta a interação social como aspecto principal para composição social e pessoal da pessoa com deficiência juntamente com diversas implicações em relação ao defeito orgânico do sujeito com deficiência, contudo Vygotsky transfere a deficiência de algo orgânico para um problema social. Observa-se que o meio social também responsável pelo desenvolvimento da pessoa com deficiência, visando sua integração. Os estudos de Vygotsky propõem que é necessário haver a inserção da pessoa com deficiência na vida social e laboral, desfocando o ensino fundamentado no defeito orgânico e valorizando o desenvolvimento das funções humanas complexas (DAINEZ, SMOLKA, 2014).

Dessa forma, na vida em sociedade, as interações indivíduo-meio produzem situações ou dificuldades que interferem na construção de novas possibilidades. É considerado um equívoco quando se é avaliado as possibilidades de desenvolvimento do sujeito com deficiência 
de acordo com sua própria deficiência pelo fato de que, as pessoas, de forma individual, elaboram dificuldades e desenvolve, processos compensatórios (DIAS, OLIVEIRA, 2013).

Entende-se que o apoio social é recebido por diferentes grupos sociais compostos por pessoas da família, amigos, vizinhos e profissionais. Esses contatos são unidos por ligações entre si formando uma espécie de rede. A densidade da rede social de pessoas diagnosticadas com deficiência intelectual apresenta pouca densidade e é caracterizada por um número limitado de pessoas. Esse apoio social interfere na autoestima, autonomia e autoconfiança do sujeito, portanto esse número limitado de integrantes da rede social que geralmente se conhecem entre si podem trazer um impacto negativo para a vida do sujeito.

Forrester-Jones et al. (2004) sugere que uma rede social de baixa densidade ou uma rede que inclua membros que não se conhecem entre si possuem uma maior chance para que os sujeitos com deficiência intelectual tenham mais espaço para criarem novas experiências sociais e de relacionamento diminuindo assim um potencial de agrupamento segregado que pode ocasionar uma certa falta de privacidade e gerar um ambiente restrito influenciado por outros.

Ressalta-se a importância de inserir pessoas com deficiência intelectual em atividades ligadas à contextos sociais para ser desenvolvido o processo de inclusão para que os mesmos tenham um maior desenvolvimento de sua autonomia e processo de escolha. A inclusão social beneficia o sujeito para se integrar em diferentes grupos sociais e assim gerando oportunidades para que ele se insira na sociedade como um ser autônomo e livre. A inserção de pessoas com deficiência intelectual no mercado de trabalho se mostra essencial para seu desenvolvimento, pois mesmo não garantindo relacionamentos sociais, o trabalho pode ajudar a aumentar o tamanho da rede social e oferecer oportunidades para essas pessoas conhecerem outras pessoas com deficiência intelectual também trazendo benefícios como um aumento de contato e nas relações próximas das redes de pessoas derivadas do trabalho (FORRESTER-JONES et al., 2004).

A tomada de decisão influencia na qualidade de vida, portanto, desde a adolescência até a fase adulta, estamos constantemente colocando essa ação em prática. A família e os contatos sociais possuem um enorme peso em cima desse processo de mudança que é evidenciado por Reichert e Wagner (2007) que afirmam que para ter o conhecimento do potencial autônomo de um sujeito, é preciso entender os modelos de relações que esse jovem constitui em sua vida social. Portanto a autonomia é vista como algo que o próprio sujeito estabelece formando uma ligação entre seu meio interno que ele mesmo organiza e as condições que os meios externos proporcionam para o seu desenvolvimento.

É necessário que o contexto familiar abra espaços para que o sujeito com deficiência intelectual descubra por si as mudanças que a fase da adolescência proporciona para se constituir como um sujeito autônomo e fomentar-se a autonomia, e "espera-se, portanto, que os pais respeitem a individualidade de seus filhos, para que eles consigam expressar sua afetividade, equilibrando assim a liberdade e, desta forma, estarão fomentando a autonomia" (REICHERT, WAGNER, 2007, p. 48).

Barbosa et al. traz a ideia de que as práticas parentais influenciam no desenvolvimento da autonomia e na forma em que um sujeito interpreta a autoridade parental (2017). Para que não haja conflitos, é importante que os familiares permitam que o jovem com deficiência 
intelectual tenha momentos de descoberta para desenvolver maneiras de lidar com situações individualmente e assim se desenvolver enaltecendo suas potencialidades.

Diante disso, é possível apontar que a sociedade atual é movida pela competição e pela dominação de forças que privilegiam e valorizam a perfeição juntamente com a estética corporal como um padrão social que se fundamenta na diferenciação de classes de forma individualizada. Isso limita as potencialidades do sujeito com deficiência e o impede que se desenvolva em sua rede social criando novas formas de superação e adaptação diante as desigualdades. Logo, torna-se necessário pensar que a deficiência não significa incapacidade e que o acesso e a promoção da igualdade conduzem o sujeito com deficiência a sua inclusão e autossuficiência.

As interações sociais e as redes sociais, efetuadas entre o homem e o meio são as que proporcionam o desenvolvimento. Permitir que esse sujeito tenha a liberdade para a interação social com destino a construção de relações favorece na formação de uma pessoa ativa para uma vida participativa exercendo sua autonomia e reduzindo situações de inferioridade. A perda da autonomia se dá quando as pessoas que compõem a rede social do sujeito com deficiência intelectual enxergam suas habilidades com negligência, colocando-a como insuficiente ou incapaz. É importante que o suporte familiar esteja presente nas situações do cotidiano, impulsionando o sujeito com deficiência a se constituir como um ser autônomo que seja capaz de fazer escolhas de acordo com seus próprios desejos, promovendo a liberdade e independência. Desse modo, isso proporcionará autonomia tanto no trabalho, no meio social e na construção de sua identidade e autopercepção.

\section{Metodologia}

Esta pesquisa se propõe refletir a relação estabelecida entre o exercício da autonomia e a rede de apoio social na percepção de adolescentes com deficiência intelectual. E, enquanto objetivos específicos, investigar como os adolescentes com deficiência intelectual percebem a relação estabelecida autonomia e rede de apoio social; mapear a rede social dos adolescentes com deficiência intelectual; e, compreender como os adolescentes com deficiência intelectual dispõem de vivências autônomas mediante esta rede social.

Para cumprir com os objetivos propostos este estudo foi inspirado na Epistemologia Qualitativa de Gonzalez Rey que compreende "os processos implicados na construção do conhecimento, pela forma de se produzir conhecimento" (GONZÁLEZ REY, 2002, p. 24), articulando entre os processos históricos, culturais, sociais e subjetivos acerca dos fenômenos humanos. A utilização desta proposta metodológica surge como possibilidade de estudar os processos subjetivos humanos tanto individuais, quanto sociais (OLIVERA, 2017).

Os participantes desta investigação foram 2 (dois) adolescentes com deficiência intelectual, Amada e Téo (nomes fictícios). Os adolescentes foram acessados por meio de uma escola pública inclusiva do Distrito Federal (DF), e só foram contatados após a anuência dos responsáveis. Ambos estão cursando a segunda etapa do Ensino Fundamental.

Amanda é uma adolescente de 13 anos, está cursando o $7^{\circ}$ ano do ensino fundamental, mora com os pais e uma irmã mais nova. Amanda de acordo com o Social Network Guide (SNG) dispõe de 21 pessoas na sua rede social de apoio, este valor responde à uma densidade de 77. Téo é um adolescente de 13 anos, está cursando o $6^{\circ}$ ano do ensino fundamental, mora 
com os pais, é filho único. Téo de acordo com o Social Network Guide (SNG) dispõe de 11 pessoas na sua rede social de apoio, este valor é condizente com uma densidade de 25.

Acerca dos procedimentos de construção das informações deste estudo foram orientados pela proposta Construtivo-Interpretativa (GONZÁLEZ REY, MITJÁNS MARTÍNEZ, 2017, p. 109) Relaciona-se com os 3 fundamentos da Epistemologia Qualitativa: o caráter construtivo-interpretativo da produção do conhecimento; a pesquisa como processo de comunicação e diálogo; e o reconhecimento da contribuição singular de cada caso estudado, segundo o modelo teórico em construção, como instância de produção do conhecimento científico (GONZÁLEZ REY, 1997). Os instrumentos utilizados para a produção de informação foram sistemas conversacionais organizados entre dinâmicas conversacionais e complemento de frases (GONZÁLEZ REY, MITJÁNS MARTÍNEZ, 2017). As dinâmicas conversacionais correspondem ao diálogo que compõe o entrevistador e o entrevistado interferido um pelo outro (DUPRET, 2017). Assim, também o complemento de frases auxilia o entrevistado a expressar processos simbólicos por meio de hipóteses construídas. Também foi utilizado o Social Network Guide (SNG) (FORRESTER-JONES, GRANT, 1997) como instrumento para mapear a rede social dos adolescentes com deficiência intelectual e as suas interações.

\section{Análise e Discussão da Informação}

Visando compreender a relação entre autonomia e rede de apoio social na percepção de adolescentes com deficiência intelectual, recorreu-se a proposta metodológica da Epistemologia Qualitativa com a finalidade de compreender o contexto cultural e social por meio da emergência das produções subjetivas acerca desta temática. Assim, investigaram-se os sentidos subjetivos que emergiram a partir do diálogo inicialmente com os adolescentes com deficiência intelectual. Desta maneira, viabilizou-se que estes indivíduos pudessem ter posicionamentos ativos, além de fomentar e implica-los no que tange ao processo de autonomia da pessoa com deficiência intelectual por meio da reflexão e na elaboração de estratégias capazes de viabilizar uma maior participação social dessas pessoas. Abaixo se apresenta o caso de Amanda e Téo, a partir de 3 (três) eixos temáticos que emergiram mediante os 3 (três) fundamentos da Epistemologia Qualitativa: o caráter construtivo-interpretativo da produção do conhecimento; a pesquisa como processo de comunicação e diálogo; e o reconhecimento da contribuição singular de cada caso estudado. O primeiro eixo refere-se à compreensão da deficiência; o segundo eixo faz alusão às amizades e ao sentimento de pertencimento; o terceiro eixo discute o exercício da autonomia e as possibilidades de tomada de decisão frente à rede social de apoio.

\section{Eixo $n^{\circ} 1$ - Compreensão acerca da deficiência}

No diálogo estabelecido com Amanda por meio do complemento de frases e da dinâmica conversacional, a adolescente expôs a seguinte compreensão sobre os aspectos circunscrevem a sua compreensão acerca da deficiência: "Ser deficiente é, tem gente que ajuda a gente, as pessoas que são" (Complemento de frase - CF). "Acrescido a isto Amanda compreende que ser adolescente e deficiente é normal" (CF). Além disso, associa ao que ela 
tem mais facilidade “... na escola eu não sou muito boa em matemática, tem muita coisa que eu sou boa em fazer, tem tanta coisa que eu esqueci tudo, vou falar qualquer um que tá na minha cabeça, andar de bicicleta" (CF). Mediante o relato de Amanda observa-se que Amanda elenca sentidos subjetivos acerca da sua deficiência que remete à circunstância de ter pessoas que à ajudam e que ser deficiente é ter alguém para proporcionar essa ajuda, contudo ela observa ter facilidade em diversos assuntos e diz não ser boa em matemática.

Além desses aspectos, Amanda se descreve como uma menina normal, e isso reflete em sua condição adolescente que também é marcada pela deficiência, isso fica claro quando associado a suas amizades quando diz "Amigos eles me ajudam quando eu preciso e eu acho que colegas também, às vezes (Dinâmica Conversacional - DC)". Amanda demonstra ainda em um processo ativo de tomada de decisão em frente sua rede de apoio quando diz "Eu tenho vários amigos (DC)" e "Ninguém me apresentou não. Eu fui chegando neles mesmo (DC)" quando perguntado sobre suas amizades. Segundo a mesma, ela só se encontra com eles na escola e alguns moram perto de sua casa e se comunicam via "WhatsApp" e segundo a adolescente "Não preciso pedir autorização pra ninguém para o uso do aparelho celular" (DC). Contudo, para sair de casa ela precisa pedir autorização para seus pais e para fazer trabalhos escolares ela afirma "eu saio de casa pra ir pra casa de uma amiga pra fazer (DC)" se sentindo como um ser autônomo para estabelecer relações de amizade e solução de conflitos.

Mediante as expressões elencadas por Amanda observa-se a emergência de sentidos subjetivos relacionados a uma vivência da adolescência que não é atravessada unicamente pela deficiência, este corrobora-se com Bissoto (2014) que apresenta o contexto social como aquele que desempenha repercussões tanto nos processos cognitivos quanto em estruturas e funções biológicas sendo as mesmas relacionadas às emoções e afetividade.

Foi de possível percepção, a partir do complemento de frases e da dinâmica conversacional, que Téo associa sua compreensão da deficiência na forma como vivencia sua adolescência e suas relações. Isso pode ser analisado quando pensa ser adolescente "Mais ou menos, é legal" (CF) corroborando quando apresenta sua maior dificuldade "Falar, é tipo falar. Eu fico às vezes com vergonha e falar com as pessoas. Eu demoro muito pra chegar em uma pessoa e falar com ela" (CF) que se associa com o seu conceito de aceitação pois o mesmo acredita que não terá aceitação por parte de outras pessoas, logo ele não se aproxima. Sua deficiência interfere na forma que ele vê o seu aprendizado, quando falado eu quero, ele responde "Passar de ano" (CF) mostrando uma preocupação em estudar e conseguir finalizar o ano letivo com notas boas quando diz que não pode "ficar sem estudar" (CF) refletindo novamente em sua deficiência e a crença para o defeito e não sua potencialidade. Quando foi remetido para Téo sobre o que acha legal, é novamente pronunciado sobre "Tirar notas boas" (CF) expondo sua preocupação a respeito do desempenho escolar.

Téo, na dinâmica conversacional, se descreve como "Eu sou Téo, eu tenho olhos verdes, cabelo preto, só" (DC) se limitando na descrição apenas de suas características físicas e eliminando aspectos subjetivos de sua personalidade que poderia ter sido trago pelo mesmo.

\section{Eixo $\mathrm{n}^{\circ} 2$ - A relação entre a amizade e ao sentimento de pertencimento}

Amanda, ao responder o complemento de frases e a dinâmica conversacional, apresenta ter vários amigos, e isso se liga ao fato dela adorar conversar com seus amigos se apresentando 
envolvida em seu contexto social e escolar com pessoas que já possui algum vínculo "Quando eu estou conversando com minhas amigas a gente conversa muito" (CF), entretanto, sendo com pessoas que ela não conhece, ela não se comunica da mesma maneira "Eu quase não converso, eu converso pouquinho" (CF). Amizade para ela significa "Quando você pode contar o que você sente pra ela ou pra ele que essa pessoa você sabe que ela é confiável e você pode falar tudo pra ela" (CF) mostrando aspectos de afetividade e proximidade, logo são considerados companheiros de aula aqueles que ela não partilha os seus sentimentos ou assuntos pessoais. Amanda traz em sua fala que possui dificuldades em fazer trabalhos com seus amigos e isso implica na forma que os seus amigos a tratam quando diz que a faz chorar "Quando acontece alguma coisa quando uma pessoa te culpa do que você não fez" (CF) e com isso, Amanda diz que odeia "Quando eu brigo com alguém" (CF) apresentado uma falta de autonomia em se impor em determinados momentos.

Nas respostas apresentadas por Amanda, durante a dinâmica conversacional, apresenta uma rede social composta por muitas pessoas de seu meio escolar quando afirma “... eu tenho vários amigos... Metade da sala é meus amigos e outra metade da sala é meus companheiros" (DC) e se mostra autônoma quando alega que "Ninguém me apresentou não. Eu fui chegando neles mesmo" (DC) em relação ao processo de escolha de amizades. Sua rede de apoio é composta pelas relações que a mesma estabelece e oferecem suporte quando há necessidade mesmo quando não é uma pessoa próxima a ela "Amigos eles me ajudam quando eu preciso e eu acho que colegas também, às vezes" (DC). Amanda conta que vê os amigos de escola perto de casa "Tem alguns que eu conheço que mora aqui perto" (DC) e isso proporciona o fortalecimento dos vínculos estabelecidos pela adolescente.

Segundo o Complemento de Frases, Téo mostra ter uma alta densidade em sua rede social em que as poucas pessoas que a compõem se conhecem, sendo eles seus professores e um amigo que o mesmo adora conversar "Com meus amigos e professores, alguns" (CF) e quando apresenta que possui apenas um amigo "Kaio, só" (CF), entretanto declara não ter "Nenhuma" (CF) dificuldade com seus amigos e acredita que amizade é "Ser verdadeiro" (CF). A partir disso, é possível apontar que há uma ausência de apoio social nos ambientes que Téo vivência e que sua deficiência interfere na forma como estabelece suas amizades. Quando foi pedido para responder o complemento eu posso, foi respondido "É que eu não tenho... eu tenho só um amigo que ele mora aqui na $\mathrm{Y}$ e eu moro na rua $\mathrm{X}$ " (CF) revelando dificuldades de locomoção e isso afeta em suas participações sociais para o estabelecimento de novos vínculos.

A partir da dinâmica conversacional, Téo traz novamente a escassez de pessoas que compõem seu círculo social sendo duas pessoas "O Kaio, Pedro Vinícius” (DC) prejudicando sua rede de apoio em momentos que o mesmo necessita de suporte pois, segundo ele, “... às vezes quando eu to com dificuldade, eles me ajuda pelo menos o Kaio", (DC) se limitando apenas a uma pessoa que oferece esse suporte. As respostas de Téo se conectam com Bissoto trazendo a ideia da necessidade de identificação para que o sujeito tenha autonomia (2014). A identificação interfere no desenvolvimento e na consolidação de relações.

\section{Eixo $n^{\circ} 3$ - $O$ exercício da autonomia e as possibilidades de tomada de decisão frente à rede social de apoio}


Para a temática a respeito do exercício da autonomia, é possível observar que Amanda possui a ideia de que está vivenciando a autonomia e tomada de decisão acerca de seus desejos quando diz "Saio com a minha mãe, eu sempre escolho algumas roupas" (CF) e quando aponta que "Posso sair, sair sozinha eu só posso ir aqui no condomínio mas sair lá fora tem que ir com meus pais“ (CF) em que seus pais a permite fazer o exercício da autonomia. Entretanto, é colocada em um lugar de atenção pelos pais por não poder falar com estranhos que a família não conhece e não poder sair sozinha a noite trazendo a ideia de dependência dos pais para determinados momentos em que os responsáveis não estão presentes.

Em suas vivências autônomas, a estudante Amanda conta que não precisa pedir autorização seus pais para o uso do celular e não se vê incapacitada quando necessita ir em algum lugar como na casa de alguma amiga "Não, preciso pedir autorização pros meus pais. Quando é pra fazer algum trabalho, eu saio de casa pra ir pra casa de uma amiga pra fazer" (DC) se sentindo um ser autônomo para estabelecer relações de amizade e solução de conflitos. Quando Amanda apresenta “... se acontecesse alguma coisa a gente mesmo que ia resolver. Mas se fosse alguma coisa grave de escola aí sim eles iam entrar" (DC) evidencia que seus responsáveis apenas intervir em situações de conflito quando é relacionado a assuntos sérios que envolvessem Amanda.

As vivências autônomas de Amanda são constatadas na literatura em que Reichert e Wagner (2007) apresenta o ser autônomo como o aquele que é capaz de ter consciência de seus desejos, da responsabilidade de suas condutas e a capacidade de manifestar seus sentimentos reconhecendo assim suas potencialidades e fragilidades.

Segundo Téo, sua tomada de decisão se refere a escolha de filmes de seu interesse, o que traz uma atenção em relação a como ele vivencia sua autonomia no dia a dia. Ele ainda traz que seus pais não o deixam ir em algum lugar só "Eu tenho um vizinho aí eu não posso ir lá sozinho, é tipo, eu moro aqui e aí ele mora ali e eu não posso ir lá só” (CF) e, portanto, isso não o possibilita fazer o exercício da autonomia.

Téo atribui características físicas quando é perguntado quem ele é, limitando suas qualidades e potencialidades. Foi possível compreender que sua rede social é baixa sendo composta por dois amigos, sendo apenas um amigo que Téo convive. Suas amizades são mediadas por um adulto, seu pai, apontando que sua autonomia é restringida. Isso também é visto quando o mesmo diz que precisa pedir autorização de seus pais para usar aparelhos eletrônicos como o celular "Eles não deixam eu mexer muito na internet porque eles fica com medo, tipo, de que com quem eu to conversando. Aí então as vezes eu só ligo ou então eu mando mensagem pro Kaio no whatsapp do celular da minha mãe (DC)". Os ambientes que o adolescente frequenta são poucos porque o mesmo alega que seus pais "Têm medo de eu com quem eu estou conversando. Eles só me deixam mandar mensagem pra eles no celular ou da minha mãe ou do meu pai que aí eles vão ver a conversa (DC)" e que "Eles ficam preocupados quando eu saio sozinho com alguém. Tanto é que quando saio, um dia eu fui sair com meu primo, a minha mãe falou pra ele me ajudar lá atravessar a rua (DC)”. Dessa forma, é marcado a ideia de que o medo que os pais vivenciam não oportuniza lugares e espaços para que o adolescente estabeleça relações com pessoas desconhecidas pela família. O mesmo teve uma resposta confusa quando foi perguntado se ele avalia ter autonomia para estabelecer amizades e o mesmo respondeu "Não. Não sei. Sim (DC)". Ao final da entrevista, foi perguntado o que mais ele gostaria de dizer na entrevista, e o mesmo respondeu "Eu só achei bom porque me fez 
assim bem, tem alguém que eu possa conversar (DC)" apresentando a necessidade de ampliação de sua rede de apoio.

Mediante a proposição de compreender a relação estabelecida entre o exercício da autonomia e a rede de apoio social na percepção de adolescentes com deficiência intelectual observou-se que os resultados obtidos pelo SNG revelaram que a rede de apoio social dos adolescentes com deficiência intelectual é composta mormente pela família nuclear, além de uma rede restrita de colegas no âmbito da escola. Infere-se que assim como "a dificuldade de locomoção física é apontada na literatura como o motivo principal de restrição na participação social" (HOLANDA et al., 2015), considera-se que a dificuldade no comportamento adaptativo, envolvendo as habilidades conceituais, sociais e práticas podem tecer uma justificativa para a restrição na rede social.

Outro dado observado relaciona-se à densidade da rede de apoio dos adolescentes com deficiência intelectual, uma vez que, a maioria dos membros estabelecem conexão e vínculo; justificando mais uma vez a emergência da ampliação das redes de apoio com vistas a ampliar a inclusão social desses adolescentes. Em face deste aspecto, avalia-se a necessidade de que os pais, ao mesmo tempo em que desejam filhos autônomos, devem acostumar-se a uma nova maneira de vivenciar seu papel parental, renunciando ao controle que antes possuíam e aceitando a menor dependência dos filhos (BARBOSA et al., 2017).

\section{Considerações Finais}

Diante disto, entende-se que o adolescente com deficiência intelectual deve ser orientado a participar ativamente da construção de sua própria história, valorizando as capacidades e o desenvolvimento do jovem na relação com seu meio, levando sempre em consideração que o ser humano não se constitui sozinho, mas é ligado por uma rede que se encontra diversos fatores históricos e sociais conectados.

Verifica-se a relevância da continuidade da presente investigação a fim de ampliar a compreensão acerca da percepção do adolescente com deficiência intelectual e seus familiares sobre a relação estabelecida entre a rede de apoio social e as possibilidades de ação autônoma da pessoa com DI frente as suas escolhas e decisões. Tendo em vista que, a promoção para o aumento da autonomia se torna significativo para que a pessoa com deficiência intelectual obtenha liberdade para seguir seus desejos e obter sentimento de pertencimento dentro de grupos sociais de acordo com seu desenvolvimento e suas experiências, pois desse modo, influenciará e valorizará positivamente na autopercepção do sujeito. 
Referências Bibliográficas

AMERICANASSOCIATION ON INTELLECTUAL AND DEVELOPMENTAL DISABILITIES - AAIDD. Definition of Intellectual Disability. Washington, D.C: AAIDD, 2016. Disponível em: <https://aaidd.org/intellectualdisability/definition\#.V18LLvkrKUk>. Acesso em 11 de jun. de 2018.

ALVES, S. B.; RIBEIRO, K. S. Q. S. Redes de apoio e pessoas com deficiência física: inserção social e acesso aos serviços de saúde. Ciência \& Saúde Coletiva. v. 20, n. 1, p. 175$184,2015$.

ASSUNÇÃO, R. Desenvolvimento humano como processo de (re)construção do sujeito no contexto de um curso de formação de professores (Dissertação). Universidade de Brasília, Brasília, 2018.

BAILEY, D. B. J. Introduction: Family adaptation to intellectual and developmental disabilities. Mental Retardation and Developmental Disabilities, Research Reviews, 2007.

BARBOSA, P. V. et al. Autonomia, Responsividade/Exigência e Legitimidade da Autoridade Parental: Perspectiva de Pais e Adolescente. USF, Bragança Paulista, v. 22, n. 1, p. 23-34, 2017.

BISSOTO, M. L. Deficiência Intelectual e processos de tomada de decisão: estamos enfrentando o desafio de educar a autonomia?. Volume 18, número 1. Centro Universitário Salesiano de São Paulo, 2014.

BRASIL. Lei $\mathbf{N}^{\circ}$ 13.146, de 6 de julho de 2015. Disponível em: < http://www.planalto.gov.br/ccivil_03/_ato2015-2018/2015/lei/113146.htm> Acesso em: 21/09/17.

CARDOZO, A.; SOARES, A. B. Envolvimento entre Pais e Filhos com Deficiência Intelectual. Psicologia: Ciência e Profissão, 2011.

COLLINS, N. L.; FEENEY, B. C. New Look at Social Support: A Theoretical Perspective on Thriving Through Relationships. Pers Soc Psychol Rev. 2015.

COLNAGO, N. A. S. Orientação para pais de crianças com síndrome de down: elaborando e testando um programa de intervenção. Universidade de São Paulo, 2000.

DAINEZ, D.; SMOLKA, A. L. B. O conceito de compensação no diálogo de Vigotski com Adler: desenvolvimento humano, educação e deficiência. Educ. Pesqui., São Paulo, v. 40, n. 4, p. 1093-1108, 2014.

DIAS, S. S; OLIVEIRA, M. C. S. L. Deficiência intelectual na Perspectiva Históricocultural: contribuições ao estudo do desenvolvimento adulto. Rev. Bras. Ed. Esp., Marília, v. 19, n.2, p. 169-182, 2013. 
DOUMA, J. C. H.; DEKKER, M. C..; KOOT, H. M. Supporting parents of youths with intellectual disabilities and psychopathology. Journal of Intellectual Disability Research, Volume 50, part 8, 2006.

DUPRET, L. O desafio da pesquisa qualitativa. Rio de Janeiro: Letra Capital, 2017.

FIAMENGHI, G. A. J.; MESSA, A. A. Pais, Filhos e Deficiência: Estudos Sobre as Relações Familiares. Psicologia, Ciência e Profissão, 2007.

FORRESTER-JONES, R.; et al. Supported Employment: a Route to Social Network. Journal of Applied Research in Intellectual Disabilities, 199-208, 2004.

FORRESTER-JONES, R.; GRANT, G. Resettlement from large psychiatric hospital to small community residence: One step to freedom? Aldershot: Ashgate Publishing Group, 1997.

HOLANDA, C. M. A. et al. Redes de apoio e pessoas com deficiência física: inserção social e acesso aos serviços de saúde. Ciência \& Saúde Coletiva, 175-184, 2015.

IBGE 2010 - Censo Demográfico 2010 - Características Gerais da População. Disponível em: <http://www.ibge.gov.br>. Acesso em 11 de jun. de 2018.

MELLO, A. G. Deficiência, incapacidade e vulnerabilidade: do capacitismo ou a preeminência capacitista e biomédica do Comitê de Ética em Pesquisa da UFSC. Ciênc. saúde coletiva, Rio de Janeiro , v. 21, n. 10, p. 3265-3276, 2016.

OLIVEIRA, A. M. C. Desenvolvimento subjetivo e educação: avançando na compreensão da criança que se desenvolve em sala de aula. Dissertação. Universidade de Brasília, Brasília, 2017.

OMS, Relatório Mundial sobre a Deficiência. Governo do Estado de São Paulo, 2011. Disponível em: <http://www.pessoacomdeficiencia.sp.gov.br/usr/share/documents/RELATORIO_MUNDIA L_COMPLETO.pdf>. Acesso em: 10 de Junho de 2019.

REICHERT, C. B.; WAGNER, A. Considerações sobre a autonomia na contemporaneidade. Estudos e pesquisas em psicologia, UERJ, Rio de Janeiro, v. 7, o 405418, 2007.

Relatório Mundial sobre a Deficiência, 2011, Governo do Estado de São Paulo.

REY, F. L G. Epistemología cualitativa y subjetividad. São Paulo: EDUC, 1997.

REY, F. L G, Pesquisa qualitativa e subjetividade: os processos de construção da informação. 2. Ed. São Paulo: Cengage Learning, 2005. 
REY, F. L. G.; MARTÍNEZ, A. M. Subjetividade: teoria, epistemologia e método. Campinas-SP: Alínea, 2017.

REY, F. L G. Pesquisa qualitativa em psicologia: caminhos e desafios. São Paulo: Thomson, 2002.

VILLELA, Flávia. IBGE: 6,2\% da população têm algum tipo de deficiência. Disponível em: <https://www.ebc.com.br/noticias/2015/08/ibge-62-da-populacao-tem-algum-tipo-dedeficiencia> Acesso em: 21/09/2017. 